\title{
Composição dos Juros Líquidos Pagos pelo Setor Público no Brasil: 2002-2017
}

\author{
Composition of net interest payments of the \\ Brazilian Government: 2002-2017
}

NELSON HENRIQUE BARBOSA-FILHO*

\begin{abstract}
RESUMO: Este artigo apresenta uma metodologia de decomposição dos juros líquidos pagos pelo setor público brasileiro em cinco itens: juros reais, correção monetária, swaps cambiais, custo da carteira financeira do governo e efeitos de segunda ordem. $\mathrm{O}$ artigo também apresenta outra metodologia com adição da senhoriagem à lista inicial. Os dados brasileiros indicam mudanças importantes na composição dos juros líquidos nos últimos 15 anos, com redução dos juros reais de 2009 de 2015, e elevação a partir de então. Os dados também mostram que o custo financeiro da carteira do governo subiu significativamente a partir de 2006, devido à acumulação de reservas internacionais pelo Banco Central e empréstimos da União ao BNDES.
\end{abstract}

PALAVRAS-CHAVE: Brasil; Finanças Públicas; Juros Pagos.

ABSTRACT: This paper presents a methodology to decompose the net interest payments of the Brazilian government in five items: real-interest payments, inflation adjustment, exchangerate swaps, financial cost of the government's portfolio and second-order effects. The paper also presents an alternative methodology in which seigniorage is added to the initial list. The Brazilian data show important changes in the composition of the net interest paid in the last 15 years, with a reduction in real-interest payments in 2009-15, and an increase since then. The data also show that the financial cost of the government's portfolio grew substantially since 2006, due to the accumulation of international reserves by the Central Bank and the government's loans to its national development bank (BNDES).

KEYWORDS: Brazil; Public Finance; Interest Payments.

JEL Classification: H60; N16; E40.

\footnotetext{
* Professor Titular da Escola de Economia de São Paulo da FGV, SP - Brasil. E-mail: nhbarbosa@gmail. com. Submetido: 11/Setembro/2017; Aprovado: 21/Dezembro/2017.
} 
O governo brasileiro enfrenta um grande desafio fiscal. A relação entre dívida pública e PIB aumentou significativamente nos últimos anos, tanto em termos líquidos quanto em termos brutos. A recuperação do equilíbrio fiscal requer um aumento do resultado primário do governo, o que por sua vez implica tanto uma recuperação de receitas quanto uma redução do gasto em proporção do PIB. Projeções de mercado indicam que será necessário um ajuste de aproximadamente $4 \%$ do PIB para estabilizar a dívida líquida do governo, isto é, R 270 bilhões com base no PIB de 2017.

Até o momento as ações das autoridades e o debate macroeconômico estão corretamente concentrados no reequilíbrio do orçamento primário, sobretudo no controle da despesa obrigatória, uma vez que sem tal medida será impossível recuperar o reequilíbrio fiscal. Apesar dessa necessidade, também é necessário analisar o orçamento financeiro do setor público, uma vez que há uma série de medidas que podem reduzir a taxa de juro implícita sobre a dívida pública e, dessa forma, diminuir o resultado primário requerido para a estabilidade fiscal.

A maioria dos modelos teóricos de dinâmica de dívida pública se concentram em cenários para o resultado primário, o crescimento do PIB e a taxa de juro real paga pelo governo, mas quando consideramos casos concretos como o brasileiro, também é necessário avaliar o efeito da taxa de câmbio e da acumulação de ativos financeiros por parte do setor público sobre a estabilidade fiscal (Barbosa-Filho, 2014a; Pinheiro e Gomes, 2015).

Por exemplo, nos últimos anos os juros líquidos pagos pelo governo brasileiro foram fortemente influenciados pelo resultado de operações de swap cambial do Banco Central do Brasil (BCB), que tem pouca ligação direta com desequilíbrios entre receita e despesa primária da União.

No mesmo sentido, uma parcela significativa dos juros pagos pelo setor público brasileiro decorre do custo de carregamento de ativos de baixa rentabilidade basicamente reservas internacionais e empréstimos ao Banco Nacional de Desenvolvimento Econômico e Social (BNDES). Esses ativos foram adquiridos por motivos estratégicos ou de estabilização financeira nos últimos anos, que também não tem uma ligação direta com o atual desequilíbrio estrutural do orçamento primário da União.

Este artigo tem por objetivo contribuir para o debate sobre política fiscal no Brasil apresentando uma metodologia de decomposição dos juros líquidos pagos pelo setor público. Com base nos dados públicos do BCB e IPEADATA, a proposta é separar o pagamento de juros propriamente ditos do resultado dos swaps cambiais do $\mathrm{BCB}$ e, em seguida, dividir o valor remanescente em três componentes principais: juros reais, correção monetária e custo de carregamento da carteira de ativos e passivos financeiros do governo.

A análise está organizada em três seções além desta introdução. A primeira seção apresenta a metodologia contábil. A segunda seção aplica essa metodologia aos dados brasileiros, de 2002 a 2017, e a última seção conclui a análise com um resumo das mudanças estruturais no pagamento de juros por parte do governo brasileiro durante tal período. 


\section{CONTABILIDADE DOS JUROS LÍQUIDOS}

Para começar, defina $D_{L, t}$ como a dívida líquida do setor público ao final do período t. $\mathrm{O}$ conceito de setor público utilizado pelo governo brasileiro inclui o $\mathrm{BCB}$ e, portanto, a base monetária é parte da dívida líquida (BCB, 2012). ${ }^{1}$ Formalmente:

$$
D_{L, t}=D_{t}+H_{t}-A_{t}
$$

onde $D_{t}$ representa a dívida bruta (títulos de renda fixa), $H_{t}$ a base monetária e $A_{t}$ os ativos financeiros do setor público.

Como por definição a base monetária não paga juros e, no caso do Brasil, o governo realiza swaps cambiais, os juros líquidos pagos sobre a dívida líquida do podem ser definidos como:

$$
J_{L, t}=i_{D, t} D_{t-1}-i_{A, t} A_{t-1}+R_{s w a p, t}
$$

onde $i_{D, t} \mathrm{e} i_{A, t}$ são as taxas de juro nominal incidentes sobre a dívida bruta e o ativo financeiro do setor público, ${ }^{2}$ respectivamente, e $R_{\text {swap }, t}$ representa o resultado dos swaps cambiais realizados pelo BCB.

Do ponto de vista contábil, swaps são direitos ou obrigações contingentes, isto é, operações que geram um fluxo de caixa positivo ou negativo de acordo com a flutuação dos índices e do valor nocional especificados no contrato. Por tratar de ativos e passivos contingentes, o estoque de swaps cambiais do BCB não aparece no conceito de dívida líquida apresentado em (1), ${ }^{3}$ mas sua existência pode afetar a evolução do endividamento público devido aos ganhos ou perdas do BCB no mercado de derivativos.

Por exemplo, no caso de uma venda de swap cambial pelo BCB, o setor público se compromete a pagar a variação cambial acrescida de uma taxa de juros - $\mathrm{o}$ cupom cambial - em troca de receber a taxa básica de juro (SELIC) sobre o valor nocional do contrato (Locatelli, 2013).

Caso a soma da depreciação cambial com o cupom cambial supere a SELIC, a perda do BCB com swaps cambiais é registrada como um pagamento de juros líquidos por parte do setor público pela metodologia adotada no Brasil. Quando o oposto acontece, o ganho do BCB gera uma receita de juros para o governo. Por

\footnotetext{
${ }^{1}$ Para excluir a base monetária da análise, seria necessário utilizar o conceito de "governo-geral", que inclui apenas as administrações federal, estadual e municipal. Como os swaps cambiais do BCB tiveram um grande impacto fiscal nos últimos anos, esse artigo analisará os dados para o setor público.

${ }^{2}$ A literatura de modelos macros normalmente define a taxa de juro paga no período $t$ como $i_{t-1}$, assumindo que tal taxa é fixada no final do período t-1 e paga no final do período $t$ (Walsh, 2010). Para simplificar a notação, eu optei por definir esse conceito como $i_{t}$.

${ }^{3}$ Teoricamente, ao realizar um swap, o governo está fazendo uma operação simultânea de compra de um ativo financeiro e a emissão de um passivo financeiro no mesmo valor, com impacto zero sobre a dívida líquida.
} 
analogia o mesmo raciocínio se aplica na direção oposta quando o BCB vende um swap cambial "reverso". 4

Voltando à definição contábil dada em (2), o primeiro passo de nossa metodologia é separar o resultado dos swaps cambiais do pagamento total de juros. Isso pode ser feito com base nos dados do BCB, que divulga os juros líquidos pagos por indexador. $^{5}$

Uma vez calculados os juros propriamente ditos sobre a dívida líquida, nosso próximo passo é utilizar uma taxa de juro de referência para avaliar o efeito da composição de passivos e ativos financeiros do setor público sobre o seu pagamento de juros. A taxa SELIC é a candidata óbvia à taxa de referência no Brasil, uma vez que teoricamente o governo poderia emitir somente títulos vinculados a tal taxa, bem como aplicar seu caixa em depósitos interfinanceiros com rendimento praticamente igual à SELIC. ${ }^{6}$

Matematicamente, utilizar a taxa SELIC para analisar a composição dos juros líquidos significa reescrever (2) como:

$$
J_{L, t}=i_{B, t}\left(D_{t-1}-A_{t-1}\right)+C_{t}+R_{\text {swap }, t}
$$

onde $i_{D, t}$ é a taxa básica de juro e

$$
C_{t}=\left(i_{D, t}-i_{B, t}\right) D_{t-1}+\left(i_{B, t}-i_{A, t}\right) A_{t-1}
$$

representa o custo de administração da "carteira financeira" do governo, isto é, o quanto custa ao governo emitir passivos e adquirir ativos atrelados a taxas de juros diferentes da SELIC.

Agora note que, com base na definição de dívida líquida dada em (1), nós podemos reescrever (3) como:

$$
J_{L, t}=i_{B, t}\left(D_{L, t-1}-H_{t-1}\right)+C_{t}+R_{\text {swap }, t}
$$

A grande vantagem de (5) em relação a (3) é que nós não precisamos saber a taxa de juro de cada passivo e ativo financeiro do governo para calcular o custo total de sua carteira. Esse valor pode ser obtido residualmente a partir da taxa básica de juro, da dívida líquida, da base monetária e do resultado dos swaps cambiais do governo em (5).

O próximo passo de nossa metodologia é separar juros reais de correção mo-

\footnotetext{
${ }^{4}$ No swap cambial "reverso" o BCB se compromete a pagar a SELIC em troca de receber a variação cambial mais cupom cambial.

${ }^{5}$ Esses dados estão na tabela "NFSP - Juros nominais por indexador”, disponível na página do BCB na internet. O resultado dos swaps cambiais foi calculado com base na série "outros", uma vez que os swaps respondem por quase $100 \%$ de tal série. Todos os dados utilizados neste artigo estão disponíveis ao leitor, mediante solicitação ao autor.

${ }^{6}$ Por exemplo, se nós considerarmos a União, a emissão de títulos poderia ser feita somente via Letras Financeiras do Tesouro (LFT), e os investimentos financeiros somente via conta única do Tesouro no BCB. Nos dois casos a taxa de juro correspondente é a SELIC.
} 
netária no pagamento de juros calculados com base na taxa SELIC. Para fazer isso, basta utilizar a definição usual da taxa de juro nominal:

$$
i_{B t}=\left(1+r_{B t}\right)\left(1+\pi_{t}\right)-1=r_{B t}+\pi_{t}+r_{B t} \pi_{t}
$$

onde $r_{B, t}$ é a taxa básica de juro real e $\pi_{t}$ a taxa de inflação.

Com base em (6) nós podemos reescrever (5) como:

$$
J_{L, t}=r_{B, t}\left(D_{L, t-1}-H_{t-1}\right)+\pi_{t}\left(D_{L, t-1}-H_{t-1}\right)+C_{t}+R_{\text {swap }, t}+S_{t}
$$

onde

$$
S_{t}=r_{B t} \pi_{t}\left(D_{L, t-1}-H_{t-1}\right)
$$

representa o termo de segunda ordem que inevitavelmente aparece quando trabalhamos com tempo discreto. Esse termo é pequeno quando fazemos a contabilidade de juros líquidos em bases mensais.

A interpretação econômica da taxonomia proposta em (7) é que o pagamento total de juros líquidos pelo governo pode ser dividido em cinco componentes:

I. Os juros reais sobre a dívida líquida não monetária, $r_{B, t}\left(D_{L, t-1}-H_{t-1}\right)$,

II. A correção monetária da dívida líquida não monetária, $\pi_{t}\left(D_{L, t-1}-H_{t-1}\right)$

III. Custo da carteira financeira do governo, $C_{t}$,

IV. resultado dos swaps cambiais do BCB, $R_{\text {swap }, t}$, e

V. Um termo de segunda ordem, $S_{t}$.

Por fim, cabe apontar que o pagamento de juros líquidos pelo governo também pode ser expresso como:

$$
J_{L, t}=r_{B, t} D_{L, t-1}+\pi_{t} D_{L, t-1}-i_{B, t} H_{t-1}+C_{t}+R_{s w a p, t}+\tilde{S}_{t}
$$

onde

$$
\tilde{S}_{t}=r_{B t} \pi_{t} D_{L, t-1}
$$

representa o termo de segunda ordem sobre a dívida líquida do governo.

Em termos econômicos, a diferença entre (7) e (9) é que em na primeira equação a taxa real de juros e a inflação são aplicadas sobre a dívida liquida não monetária $\left(D_{L, t-1}-H_{t-1}\right)$, enquanto na segunda equação isso é feito sobre toda a dívida líquida $\left(D_{L, t-1}\right)$.

O ganho de informação de (9) é incluir uma das possíveis definições de senhoriagem $\left(i_{B, t} H_{t-1}\right)$ como um item que explicitamente reduz os juros líquidos pagos pelo governo (Buiter, 2007). Para simplificar a exposição, na próxima seção nós analisaremos os dados brasileiros somente com base (7), o que tende a subestimar o pagamento de juros reais pelo governo devido à dedução da senhoriagem dos juros nominais antes de sua divisão entre juros reais e correção monetária. $\mathrm{O}$ anexo apresenta a decomposição proposta em (9). 


\section{EVOLUÇÃO E COMPOSIÇÃO DOS JUROS LÍQUIDOS DESDE 2002}

O BCB disponibiliza estatísticas fiscais detalhadas do setor público brasileiro, com início em dezembro de 2001 e frequência mensal. Com base na metodologia apresentada na seção anterior, essa seção apresenta a contabilidade dos juros líquidos pagos pelo governo brasileiro no período de 2002 a 2017. Os dados foram calculados em bases mensais e depois consolidados no total acumulado em 12 meses. Para simplificar a exposição, todos os números serão apresentados em proporção do PIB nominal nesta seção.

Começando pelo o pagamento total de juros líquidos (Gráfico 1), os números do BCB apontam dois "picos" de despesa: em 2003 e 2015, quando o valor total chegou a $8,4 \%$ do PIB. Durante a maior parte do período em análise o pagamento de juros líquidos flutuou entre $5 \%$ e $7 \%$ do PIB, o que aparentemente indica uma estabilidade a despeito das mudanças da política fiscal e da redução da dívida líquida observadas na maior parte do período em questão.

Gráfico 1: Brasil juros liquídos pagos pelo setor público, em \% do PIB

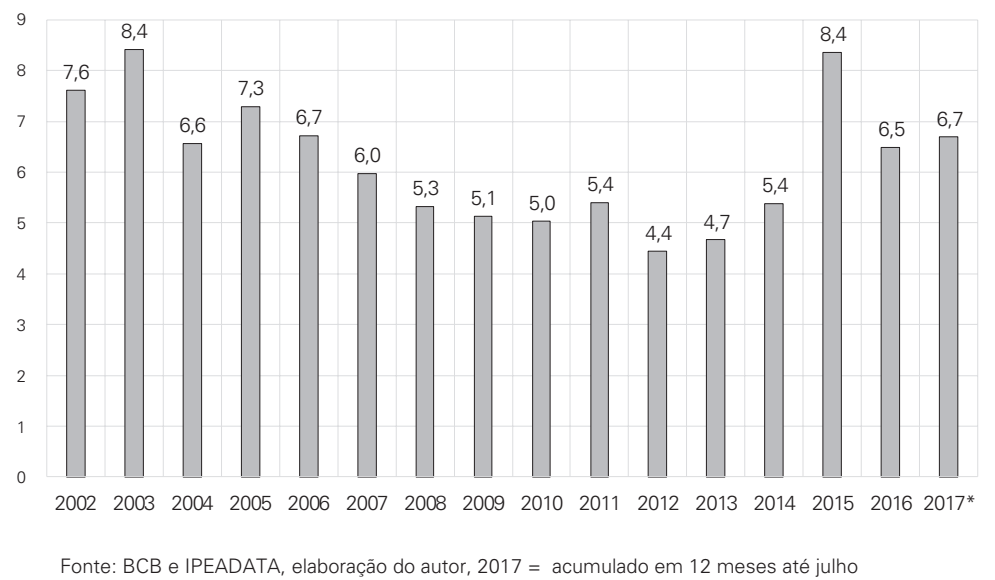

Para se obter os juros propriamente pagos sobre a dívida líquida é necessário excluir o resultado dos swaps cambiais da série agregada apresentada pelo BCB. Quando nós fazemos isso (gráfico 2), os dados indicam que o maior pagamento de juros líquidos propriamente ditos ocorreu em 2003, quando tal despesa atingiu 8,3\% do PIB.

Em 2015, quase um quinto dos juros líquidos totais pagos pelo setor público decorreu das perdas do BCB com swaps cambiais, que atingiram 1,5\% do PIB em tal ano. Esse foi o maior valor registrado desde 2002 e reflete a decisão do governo brasileiro de oferecer uma proteção (hedge) cambial excessiva ao setor privado durante o período de maior volatilidade financeira em 2014 (Barbosa-Filho, 2014b).

A partir de 2016, com a apreciação do Real, a situação se inverteu e o governo praticamente zerou sua perda com swaps cambiais. Mais especificamente, o ganho líquido com swaps cambiais foi de 1,2\% do PIB, em 2016, e 0,3\% do PIB nos 12 meses acumulados até julho de 2017. 
Gráfico 2: Brasil: Juros líquidos pagos pelo setor público, em \% do PIB

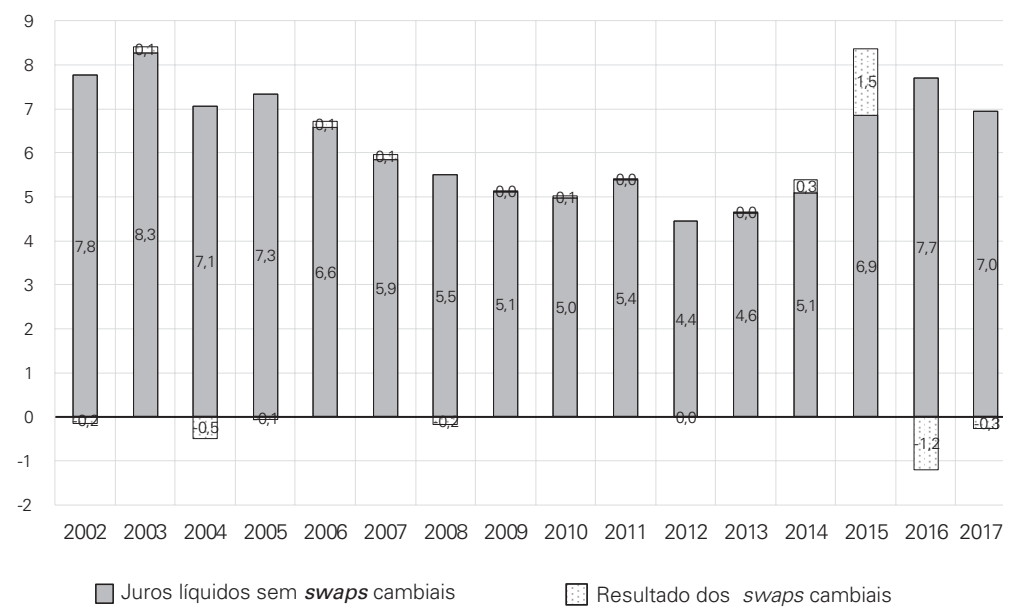

Fonte: BCB e IPEADATA, elaboração do autor, 2017 = acumulado em 12 meses até julho

Considerando apenas a série sem swaps cambiais, os dados do BCB também indicam que o pagamento de juros aumentou substancialmente em 2015 e 2016, atingindo $6,9 \%$ e $7,7 \%$ do PIB, respectivamente. Essa elevação decorreu de fatores bem diferentes em cada um desses dois anos (Gráfico 3).

Em 2015 houve uma grande elevação do custo de carteira, devido à elevação da taxa SELIC em face da baixa remuneração dos principais ativos financeiros do governo - reservas internacionais e empréstimos ao BNDES. A aceleração da inflação também contribuiu para o aumento do pagamento de juros em 2015, quando a correção monetária aumentou em 1,2 ponto percentual (pp) do PIB. Em contrapartida, o pagamento de juros reais caiu para um dos seus menores níveis no período em questão, $0,7 \%$ do PIB.

Já em 2016 houve uma grande elevação dos juros reais pagos pelo setor público - quase 2 pp do PIB - devido à manutenção da SELIC em um patamar elevado mesmo diante da queda da inflação. Esse movimento também reduziu a parcela dos juros líquidos que corresponde à correção monetária. O custo de administração de carteira também caiu ligeiramente em 2016, devido aos efeitos da elevação gradual da Taxa de Juro de Logo Prazo (TJLP), que remunera os empréstimos da União ao BNDES, ${ }^{7}$ e ao início do pré-pagamentos do BNDES à União. ${ }^{8}$

\footnotetext{
${ }^{7}$ O ajuste macroeconômico do início do segundo mandato de Dilma Rousseff incluiu a elevação da TJLP, de $5 \%$ aa, no final de 2014, para 7,5\% aa, no final de 2015 . O impacto fiscal total dessa elevação só se materializou em 2016.

${ }^{8}$ A primeira operação nesse sentido ocorreu em janeiro de 2016, ainda no governo Dilma Rousseff.
} 
Gráfico 3: Brasil: Composição dos Juros Líquidos Pagos pelo Setor Público, excluindo swaps cambiais e efeitos de 2a ordem, valores acumulados em 12 meses, em \% do PIB

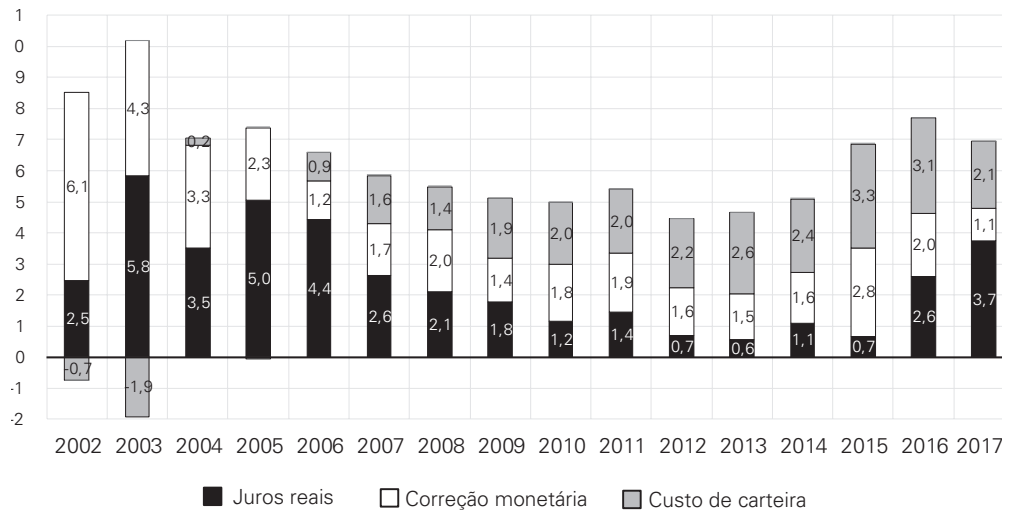

Fonte: BCB e IPEADATA, elaboração do autor, 2017 = acumulado em 12 meses até julho

Considerando o período de 2002 a 2017 como um todo, a taxonomia proposta nesse artigo revela mudanças importantes da composição do custo financeiro do governo, quais sejam:

(i) A correção monetária respondeu pela maior parcela do pagamento de juros líquidos no último ano do governo FHC, em 2002, quando o custo de carteira teve um impacto negativo. Esse último resultado indica que o governo conseguiu financiar sua dívida líquida a uma taxa inferior à taxa básica de juro naquele ano. $\mathrm{O}$ mesmo resultado aparece no primeiro ano do governo Lula, quando a SELIC subiu temporariamente acima do custo médio de captação do Tesouro. ${ }^{9}$

(ii) O primeiro mandato do Presidente Lula foi caracterizado pela redução da parcela dos juros dedicadas à correção monetária - devido à queda da inflação - e pela elevação dos juros reais pagos pelo setor público. Em média, o governo brasileiro pagou 4,7\% e 2,8\% do PIB em juros reais e correção monetária em 2003-06, respectivamente.

(iii) O custo da carteira de ativos e passivos do governo começou a subir em 2006 e continuou nessa direção durante o segundo mandato do Presidente Lula. Os principais determinantes desse processo foram a acumulação de reservas internacionais (a partir de 2006) e os empréstimos da União ao BNDES (a partir de 2009). No sentido contrário, o pagamento médio de juros reais caiu para 1,9\% do PIB em 2007-10, enquanto média de gasto com correção monetária foi de 1,7\% do PIB.

(iv) $\mathrm{O}$ custo da carteira de ativos e passivos financeiros continuou a subir durante o primeiro mandato da Presidente Dilma Rousseff, chegando a 2,6\% do PIB em 2013. Essa elevação ocorreu mesmo em um contexto de queda da taxa real

\footnotetext{
${ }^{9}$ Nesse período o governo brasileiro tinha dívida junto ao FMI, a uma taxa de juro relativamente baixa quando comparada à SELIC.
} 
de juros, isto é, a redução da SELIC foi mais do que compensada pela redução da rentabilidade e pelo aumento do volume de ativos financeiros do governo. O primeiro mandato da Presidente Dilma também registrou o menor pagamento de juros reais da série, 0,6\% do PIB em 2013. Em média, os juros reais e a correção monetária foram de $0,9 \%$ e 1,6\% do PIB em 2011-14, respectivamente.

(v) A crise política e econômica de 2015 derrubou o pagamento de juros reais e elevou o custo de carteira em tal ano, além de aumentar as perdas do BCB com swaps cambiais, como já foi mencionado anteriormente.

(vi) A partir do início do governo Temer, em maio de 2016, o pagamento de juros reais subiu rapidamente, atingindo 3,7\% do PIB nos 12 meses acumulados até julho de 2017. Devido à queda da inflação, a correção monetária se moveu na direção inversa, caindo para 1,1\% do PIB em julho de 2017. Também vale destacar que o peso do custo de carteira caiu em 1,2 pp do PIB entre o final de 2015 e meados de 2017, puxado pela elevação da TJLP e pelos pagamentos antecipados do BNDES à União, mencionado anteriormente.

Antes de prosseguir cabe apontar que os efeitos de segunda ordem no pagamento de juros líquidos foram praticamente zero ao longo do período em análise. O valor máximo verificado foi de $0,02 \%$ do PIB, em 2003-05, como apresentado no anexo.

As expectativas mais recentes do mercado indicam que a economia brasileira deve voltar a crescer nos próximos anos, com redução das taxas de juro real e de inflação. Esse cenário, combinado com a redução do custo da carteira financeira do governo, pode reduzir o pagamento de juros pelo setor público para menos de $4 \%$ do PIB nos próximos anos, o que por sua vez diminuirá significativamente o resultado primário necessário para estabilizar a dívida pública em proporção do PIB.

\section{CONCLUSÃO}

A composição dos juros líquidos pagos pelo setor público variou substancialmente desde 2002. A partir de uma metodologia contábil é possível identificar uma tendência de redução do pagamento de juros reais a partir de 2006, quando também começa uma tendência de crescimento do custo de carregamento de ativos financeiros de baixa remuneração por parte do governo, devido à acumulação de reservas internacionais pelo BCB e empréstimos da União ao BNDES.

A queda dos juros reais se interrompeu em 2016, com o início do governo Temer. Esse movimento reflete a manutenção da SELIC em um patamar elevado mesmo diante de uma rápida desinflação. Apesar dessa decisão do $\mathrm{BCB}$, a queda da correção monetária e a redução do custo de carteira do governo - devido à redução de ativos da União junto ao BNDES e à elevação da TJLP - contribuíram para a estabilidade do pagamento de juros líquidos pelo setor público recentemente.

Do ponto de vista de política econômica, as mudanças da composição dos juros líquidos pagos desde 2002 indicam que a administração do "orçamento financeiro" pode ser um instrumento importante de ajuste ou desajuste fiscal. Por 
exemplo, a redução dos empréstimos do governo ao BNDES e uma eventual diminuição do volume de reservais internacionais pode diminuir substancialmente o resultado primário requerido para estabilizar a dívida pública nos próximos anos.

O governo brasileiro já iniciou a redução de seus ativos junto ao BNDES no início de 2016 e deve aumentar essa ação no próximo ano. No caso das reservas internacionais, a experiência internacional e a própria história econômica brasileira indicam que é mais prudente esperar a recuperação da economia e ajustes mais duradouros no orçamento primário do governo antes de se tomar qualquer iniciativa de redução de custo financeiro do setor público via venda de divisas internacionais.

Se o governo conseguir realizar reforma fiscais que efetivamente controlem o crescimento de seu gasto obrigatório, a dinâmica da dívida líquida do setor público pode melhorar rapidamente mediante a combinação de redução da taxa de juro real e do custo da carteira financeira do governo.

Atualmente as expectativas de mercado apontam nessa direção, mas o pagamento de juros reais pelo setor público aumentou em aproximadamente $3 \mathrm{pp}$ do PIB desde 2015. Esse resultado indica que, pelo menos até meados de 2017, o aumento da credibilidade da política econômica foi conquista a um preço bem elevado. O verdadeiro desafio macroeconômico começará se e quando os pagamentos de juros reais por parte do setor público voltarem a cair abaixo de $2 \%$ do PIB brasileiro, como ocorreu entre 2009 e 2015.

\section{REFERÊNCIAS BIBLIOGRÁFICAS}

Barbosa-Filho, N.H. (2014A). "Resultado Primário, Dívida Líquida e Dívida Bruta: Um Modelo Contábil”, em: Regis Bonelli, Fernando Veloso. (Org.). Ensaios IBRE de Economia Brasileira II. Rio de Janeiro: Elsevier.

Barbosa-Filho, N.H. (2014B). “O desafio macroeconômico de 2015-2018”. Revista de Economia Política (Online), v. 35, p. 403-425, 2015, http://dx.doi.org/10.1590/0101-31572015v35n03a02.

BCB (2012). Manual de Estatísticas Fiscais. Brasília: Banco Central do Brasil, http://www.BCBb.gov.br/ $\mathrm{ftp} /$ infecon/Estatisticasfiscais.pdf.

Buiter, W. (2007). “Seignioriage”, NBER working paper 12919, http://www.nber.org/papers/w12919. pdf.

Locatelli, C. (2013), “BCB leiloa swaps cambiais. O que é swap cambial?”, Blog Frações Financeiras, http://www.f2br.com/cesarlocatelli/?p=712, acesso em 03/09/2017.

Pinheiro, T. e Gomes, E. (2015). The Fiscal Maze III: Insurgent”, Relatório de Mercado do Departamento Econômico do Banco Santander, São Paulo: Santander, https://www.santander.com.br/ document/wps/macroeconomic_research_151029.pdf.

Walsh, C.E. (2010). Monetary Theory and Policy. Cambridge: The MIT Press. 
ANEXO: CONTABILIDADE DOS JUROS LÍQUIDOS

PAGOS PELO SETOR PÚBLICO, EM \% DO PIB

Tabela 1: Contabilidade sem cálculo direto da senhoriagem (metodologia 1)

\begin{tabular}{|c|r|r|r|r|r|r|}
\hline Ano & Total & Juros reais & $\begin{array}{c}\text { Correção } \\
\text { monetária }\end{array}$ & $\begin{array}{c}\text { Custo de } \\
\text { carteira }\end{array}$ & $\begin{array}{c}\text { Swaps } \\
\text { cambiais }\end{array}$ & $\begin{array}{c}\text { Efeitos de 2a } \\
\text { ordem }\end{array}$ \\
\hline 2002 & 7,61 & 2,45 & 6,06 & $-0,74$ & $-0,16$ & $-0,01$ \\
\hline 2003 & 8,42 & 5,84 & 4,34 & $-1,91$ & 0,13 & 0,02 \\
\hline 2004 & 6,56 & 3,50 & 3,32 & 0,21 & $-0,49$ & 0,02 \\
\hline 2005 & 7,28 & 5,04 & 2,34 & $-0,06$ & $-0,06$ & 0,02 \\
\hline 2006 & 6,72 & 4,44 & 1,25 & 0,90 & 0,13 & 0,01 \\
\hline 2007 & 5,98 & 2,62 & 1,67 & 1,56 & 0,12 & 0,01 \\
\hline 2008 & 5,32 & 2,10 & 2,00 & 1,39 & $-0,17$ & 0,01 \\
\hline 2009 & 5,13 & 1,76 & 1,41 & 1,94 & 0,02 & 0,01 \\
\hline 2010 & 5,03 & 1,15 & 1,82 & 1,99 & 0,06 & 0,00 \\
\hline 2011 & 5,41 & 1,45 & 1,90 & 2,05 & 0,01 & 0,01 \\
\hline 2012 & 4,44 & 0,68 & 1,56 & 2,20 & $-0,01$ & 0,00 \\
\hline 2013 & 4,67 & 0,56 & 1,49 & 2,59 & 0,03 & 0,00 \\
\hline 2014 & 5,39 & 1,10 & 1,61 & 2,37 & 0,30 & 0,00 \\
\hline 2015 & 8,36 & 0,67 & 2,85 & 3,35 & 1,49 & 0,00 \\
\hline 2016 & 6,49 & 2,59 & 2,05 & 3,05 & $-1,21$ & 0,01 \\
\hline $201 *^{*}$ & 6,69 & 3,73 & 1,08 & 2,15 & $-0,27$ & 0,01 \\
\hline
\end{tabular}

Fonte: BCB e IPEADATA, elaboração do autor.

Tabela 2: Contabilidade com cálculo da senhoriagem (metodologia 2)

\begin{tabular}{|l|r|r|r|r|r|r|r|}
\hline Ano & Total & Juros reais & $\begin{array}{c}\text { Correção } \\
\text { monetária }\end{array}$ & $\begin{array}{c}\text { Custo de } \\
\text { carteira }\end{array}$ & $\begin{array}{c}\text { Swaps } \\
\text { cambiais }\end{array}$ & Senhoriagem & $\begin{array}{c}\text { Efeitos de } \\
2^{\text {a }} \text { ordem }\end{array}$ \\
\hline 2002 & 7,61 & 2,64 & 6,51 & $-0,74$ & $-0,16$ & $-0,63$ & $-0,01$ \\
\hline 2003 & 8,42 & 6,29 & 4,68 & $-1,91$ & 0,13 & $-0,80$ & 0,02 \\
\hline 2004 & 6,56 & 3,78 & 3,59 & 0,21 & $-0,49$ & $-0,54$ & 0,02 \\
\hline 2005 & 7,28 & 5,49 & 2,54 & $-0,06$ & $-0,06$ & $-0,65$ & 0,02 \\
\hline 2006 & 6,72 & 4,87 & 1,37 & 0,90 & 0,13 & $-0,56$ & 0,01 \\
\hline 2007 & 5,98 & 2,91 & 1,86 & 1,56 & 0,12 & $-0,48$ & 0,01 \\
\hline 2008 & 5,32 & 2,35 & 2,24 & 1,39 & $-0,17$ & $-0,50$ & 0,01 \\
\hline 2009 & 5,13 & 1,98 & 1,59 & 1,94 & 0,02 & $-0,40$ & 0,01 \\
\hline 2010 & 5,03 & 1,30 & 2,07 & 1,99 & 0,06 & $-0,40$ & 0,00 \\
\hline 2011 & 5,41 & 1,64 & 2,17 & 2,05 & 0,01 & $-0,47$ & 0,01 \\
\hline 2012 & 4,44 & 0,78 & 1,81 & 2,20 & $-0,01$ & $-0,34$ & 0,00 \\
\hline 2013 & 4,67 & 0,65 & 1,72 & 2,59 & 0,03 & $-0,32$ & 0,00 \\
\hline 2014 & 5,39 & 1,27 & 1,86 & 2,37 & 0,30 & $-0,41$ & 0,00 \\
\hline 2015 & 8,36 & 0,76 & 3,25 & 3,35 & 1,49 & $-0,50$ & 0,00 \\
\hline 2016 & 6,49 & 2,87 & 2,28 & 3,05 & $-1,21$ & $-0,51$ & 0,01 \\
\hline $2017^{*}$ & 6,69 & 4,08 & 1,18 & 2,15 & $-0,27$ & $-0,47$ & 0,01 \\
\hline
\end{tabular}

Fonte: BCB e IPEADATA, elaboração do autor. 